\title{
A Study on Antiurolithiatic Activity of Melia Azadirachta L. Aqueous Extract in Rats
}

\author{
Nagiat T Hwisa ${ }^{1}$, Fathi H Assaleh ${ }^{1}$, Sumalatha Gindi ${ }^{2}$, Fauzi El Melad ${ }^{1}$, Babu Rao Chandu ${ }^{1,3, *}$, Prakash \\ Katakam $^{1,3}$ \\ ${ }^{1}$ Faculty of Pharmacy, University of Zawia, Az Zawiyah, Libya \\ ${ }^{2}$ Department of Pharmacology, Hindu College of Pharmacy, Guntur, India \\ ${ }^{3}$ Priyadarshini Institute of Pharmaceutical Education and Research, Guntur, India \\ *Corresponding author: drchandubaburao@gmail.com
}

Received January 08, 2014; Revised January 26, 2014; Accepted February 08, 2014

\begin{abstract}
The objective was to investigate the antiurolithiatic activity of aqueous plant extract of Melia azadirachta using the zinc disc implantation model in male Wistar albino rats. A significant increase in urinary excretion of calcium, oxalate, magnesium and phosphate was observed after four weeks of implantation of zinc discs. After treatment with aqueous extract of Melia azadirachta caused a significant reduction $(p<0.001)$ in stone weight and urinary excretion of electrolytes in both the preventive and curative group of animals as compared to those of control groups. This explains the effect of the aqueous extract of Melia azadirachta in preventing urolithiasis (59\%) and dissolving the pre-formed magnesium ammonium phosphate type of stones (46\%). The possible mechanism could be due to the urinary stone-formation, lowering, antioxidant, diuretic, nephroprotective constituents present in Melia azadirachta. These results suggest the usefulness of aqueous plant extract of Melia azadirachta as an antiurolithiatic agent.
\end{abstract}

Keywords: Melia azadirachta, antiurolithiatic activity, aqueous extract, rats

Cite This Article: Nagiat T Hwisa, Fathi H Assaleh, Sumalatha Gindi, Fauzi El Melad, Babu Rao Chandu, and Prakash Katakam, "A Study on Antiurolithiatic Activity of Melia Azadirachta L. Aqueous Extract in Rats." American Journal of Pharmacological Sciences, vol. 2, no. 1 (2014): 27-31. doi: 10.12691/ajps-2-1-6.

\section{Introduction}

Urolithiasis is the third most common disease of the urinary tract and it has affected the human beings since the earliest days. Symptoms of urinary stone disease vary according to the location and size of the calculi. Kidney stones often move through the urinary tract and leave the body without any symptoms at all. Such stones are referred to as "silent" stones and are usually very small (< $4 \mathrm{~mm}$ ). Larger calculi cannot be excreted and even small ones can cause problems by becoming lodged in the ureter, the long narrow tube that carries urine from the kidney to the bladder.

Renal stone formation appears higher than normal in children and adults with Cushing's syndrome, elevated levels of parathyroid hormone increase the incidence of stone formation. Sarcoidosis and other granulomatous diseases, osteoporosis, inflammatory bowel disease, gout and hyperuricemia increases the incidence of kidney stones. Persons with recurrent urinary tract infections are more susceptible for kidney stones [1].

Excessive antacid use has been reported to induce hypophosphatemia, hypercalciuria and elevated plasma [1], 25-dihydroxy Vitamin D, all contributing to the increased incidence of renal stones. Long term ingestion of oral contraceptives reduces vitamin B6 levels, Protease inhibitors for HIV induce renal stone formation. Long term use of some diuretics like triamterene has also been known to contribute to urolithiasis. Sulfonamides and carbonic anhydrase inhibitors cause urolithiasis up to $1.6 \%[2]$.

Extracorporeal Shock Wave Lithotripsy (ESWL) has been the most frequently used procedure for the treatment of kidney stones. In ESWL shock waves that are created outside the body travel through the skin and body tissues until they hit the densor stones. The stones break down into sand like particles and are passed through the urinary tract in the urine. There are several types of ESWL devices. In one device, the patient reclines in a water bath while the shock waves are transmitted. Other devices have a soft cushion on which the patient lies. Most devices use either x-rays or ultrasound to help the surgeon to pinpoint the stone during treatment. For most types of ESWL procedures, anaesthesia is needed.

The recognition of different types of urinary calculi also resulted in more varieties of medical treatment. Still recurrence rates continue to be high with one of every two patients having another stone within 5 years [3]. So, there is a need to develop new drugs to prevent the recurrence of kidney stones.

In most cases of the urolithiasis, the common component is either calcium oxalate (75-90\%) or magnesium ammonium phosphate to an extent of $5-10 \%$ $[4,5,6]$. Many remedies have been employed during ages 
to treat urinary stones. Most of the remedies were taken from plants and proved to be useful. Though the rationale behind their use is not well established except for a few plants and some proprietary composite herbal drugs. We have studied earlier on antiurolithiatic activity on Macrotyloma uniflorum and Ageratum conyzoides in rats $[7,8]$.

Melia azadirachta is a tree in the mahogany family of Meliaceae. It is native to tropical and sub-tropical regions of Pakistan, India, Thailand, Nepal and Bangladesh. It is a most important medicinal plant that has been declared as the "Panacea for all diseases" [9,10]. The chemical constituents found all parts more specifically in the leaves, bark and seeds are azadirachtin, 3-deacetylsalannin, salannol, meliantriol, nimbin, ascorbic acid, 17hydroxyazadiradione and nimbiol, n-hexacosanol, amino acid, 7-desacetyl-7-benzoylgedunin, 7-desacetyl-7benzoylazadiradione [9,11]. Therapeutically, the crude extracts of leaves and bark have been used to control diseases such as intestinal helminthiasis, leprosy and respiratory disorders [12]. Several biological and pharmacological activities were reported on antipyretic, antifungal, anti-inflammatory, antiviral, antibacterial, antiparalitic, antiseptic and antimalarial uses [12,13,14,15]. In Indian indigenous system of medicine, Melia azadirachta was reported to be useful in the treatment of urinary stones [16] The present study was planned to establish the scientific evidence of the antiurolithiatic activity of Melia azadirachta aqueous extract using the zinc disc implantation model in albino rats.

The animal model of urolithiasis involving tubular dysfunction or injury by implantation of zinc disc in the urinary bladder of male albino rats to induce struvite stones [17]. It is also aimed to find out the influence of the plant extract on urinary electrolytes which play an important role in urolithiasis.

\section{Materials and Methods}

\subsection{Identification of Selected Medicinal Plants}

All the above plants were authenticated in the Department of Botany, Hindu College, Guntur. Andhra Pradesh, India. The plant specimens were deposited in the College herbarium at Hindu College of Pharmacy, Guntur, Andhra Pradesh, India.

\subsection{Preparation of Aqueous Extact}

The aerial parts of plant material were collected, shade dried and powdered coarsely. The powder was decocted in purified boiling water in the ratio of 1: 16. The decoction was then filtered, weight/ml was estimated randomly and was administered freshly to the animals by gastric intubation.

\subsection{Animals}

Sprague dawley male albino rats weighing 150-200 g were used for the present study. They were housed in groups of four under standard laboratory conditions (temperature $25 \pm 1^{\circ} \mathrm{C}$, relative humidity $55 \pm 5 \%$ and 12.00: 12.00 h dark: light cycle) with standard pellet diet and water ad libitum. The experiments were performed as per the guidelines of the Committee for the Purpose of Control and Supervision of Experiments on Animals (CPCSEA), Government of India. The Institutional Animal Ethics Committee approved the study protocol (IAEC/HCOP/06/2010).

\subsection{Foreign Body Insertion Technique}

The foreign body insertion technique was used in the to induce stones in the urinary bladder $[18,19]$. Zinc discs of $4 \mathrm{~mm}$ diameter weighing around 40-50 mg were used as foreign body. Rats were anaesthetized with ketamine (50 $\mathrm{mg} / \mathrm{kg} / \mathrm{I} . \mathrm{M}$ ) and xylazine (5 $\mathrm{mg} / \mathrm{kg} / \mathrm{I} . \mathrm{M})$. A suprapubic incision was made and the urinary bladder was exposed. A small cut was made at the tip of the urinary bladder. The $\mathrm{pH}$ of the urine was determined using absorbable 3-0 chromic catgut (Ethicon). The muscle was closed in layers using catgut and skin was closed using silk thread. The rats were allowed to recover from the operation.

All the animals were divided into four groups. Group 1 served as Preventive control and treated with distilled water only for the first four weeks. Group 2 served as Preventive group which received the aqueous extract of Melia azadirachta for four weeks. Group 3 served as curative control and treated with distilled water, only from the fourth week onwards. Group 4 served as curative group which received the aqueous extract of Melia azadirachta from the fourth week onwards. The doses of the extract selected for the present study are $400 \mathrm{mg} / \mathrm{kg}$ body weight of both the extracts. The dose was optimized based on an oral acute toxicty study performed according to OECD-423 guidelines at dose range 50 to $2000 \mathrm{mg} / \mathrm{kg}$. No mortality was observed in animals at the dose range of $300-500 \mathrm{mg} / \mathrm{kg}$. Hence $400 \mathrm{mg} / \mathrm{kg}$ was selected for the present study $[20,21]$.

Animals that died during the study were excluded from evaluation. $24 \mathrm{~h}$ urine samples were collected at the end of the fourth week in all the four groups. At the end of eighth week, $24 \mathrm{~h}$ urine samples were collected in curativecontrol and curative groups to determine urinary $\mathrm{pH}$, calcium [22] oxalate, magnesium [23] and phosphate [24].

The rats were sacrificed, zinc discs along with adhered crystals from the urinary bladders of individual rats were removed, washed in distilled water and were allowed to dry $[25,26]$. The dried discs were weighed and the difference between the initial and final weights of zinc discs gave the weight of the stone deposited [21].

\section{Results}

A significant amount of stone deposition on the zinc discs was observed in all the groups. Quantitative analysis of the stones based on surface and weight indicated that the large stones formed were of magnesium ammonium phosphate (struvite) type with traces of calcium and oxalate [17].

The mean weight of stone deposited in different groups is shown in plate 1 and comparison of stone material deposited in preventive-control is tabulated in Table 1.

Treatment with aqueous extract of Melia azadirachta for four weeks significantly reduced the amount of stone deposited in preventive group when compared to its 
preventive-control group. This shows that the extract has a significant effect $(p<0.001)$ in preventing the formation of magnesium ammonium phosphate type of stones.

Table 1. Effect of Aqueous extract of Melia azadirachta on stone weight

\begin{tabular}{|c|c|c|}
\hline S. No. & Group & Stone weight (mg) \\
\hline I & Preventive Control & $298 \pm 15.43$ \\
\hline II & Preventive & $152.6 \pm 5.89^{*}$ \\
\hline III & Curative-control & $653.1 \pm 21.01$ \\
\hline IV & Curative & $397.2 \pm 18.10^{*}$ \\
\hline
\end{tabular}

${ }^{*} p<0.001$ compared to respective control groups

Significant reduction in the weight of stone deposited was observed in the curative group when compared to its curative-control group on treatment with aqueous extract of Melia azadirachta for four weeks. This indicates the significant $(p<0.001)$ effect of the extract in dissolving the stones in the curative group as shown in Table 1.

The $\mathrm{pH}$ of urine in normal animals is between 6.0 and 7.0. On the induction of calcium oxalate stones in both the control groups, the $\mathrm{pH}$ was reduced to 5.0-6.0. On treatment with aqueous extract of Melia azadirachta the $\mathrm{pH}$ is brought back to normal between 5.5 and 7.0 in both preventive and curative groups. The electrolyte profile of various urinary constituents before implantation, four weeks after implantation and after completion of the study are shown in Table 2. There was a significant increase in the excretion of calcium, oxalate, magnesium and phosphate in I, III and IV groups after four weeks of implantation. A comparison of stone material deposited on zinc discs in various groups is shown in Figure 1.

In the preventive group (II) animals, treatment with aqueous extract Melia azadirachta significantly $(p<0.001)$ reduced the urinary excretion of calcium, oxalate, magnesium and magnesium ions when compared to its control group (I).

Similarly, in the curative group (IV) animals there was a significant reduction in the excretion of calcium, oxalate, magnesium and phosphate on treatment with aqueous extract of Melia azadirachta for four weeks when compared to its control group (III) $(p<0.001)$.

Table 2. Antiurolithiatic Activity of Melia azadirachta Urinary Electrolyte Data

\begin{tabular}{|c|c|c|c|c|c|c|}
\hline \multirow{2}{*}{ S. No } & \multirow{2}{*}{ Group } & \multirow{2}{*}{ Time of Urine Analysis } & \multicolumn{4}{|c|}{ Electrolyte Concentration (mg/dl) } \\
\hline & & & Calcium & Oxalate & Magnesium & Phosphate \\
\hline \multirow{2}{*}{ I } & \multirow{2}{*}{ Preventive-control } & $\mathrm{A}$ & $0.98 \pm 3.97$ & $0.54 \pm 0.22$ & $2.55 \pm 0.31$ & $69.4 \pm 3.09$ \\
\hline & & $\mathrm{C}$ & $2.92 \pm 0.086^{\mathrm{a}}$ & $8.95 \pm 0.501^{\mathrm{a}}$ & $8.85 \pm 0.375^{\mathrm{a}}$ & $145.12 \pm 2.69^{\mathrm{a}}$ \\
\hline \multirow{2}{*}{ II } & \multirow{2}{*}{ Preventive } & A & $1.115 \pm 0.05$ & $0.91 \pm 0.108$ & $1.525 \pm 0.148$ & $76.05 \pm 0.88$ \\
\hline & & $\mathrm{C}$ & $1.87 \pm 0.152^{b}$ & $3.25 \pm 0.53^{b}$ & $6.026 \pm 0.114^{b}$ & $101.32 \pm 3.05^{b}$ \\
\hline \multirow{3}{*}{ III } & \multirow{3}{*}{ Curative-control } & A & $1.3066 \pm 0.150$ & $3.01 \pm 0.12$ & $2.25 \pm 0.045$ & $65.06 \pm 2.024$ \\
\hline & & $\mathrm{B}$ & $4.57 \pm 0.156^{\mathrm{a}}$ & $4.85 \pm 0.09^{\mathrm{a}}$ & $7.153 \pm 0.068^{\mathrm{a}}$ & $149.51 \pm 1.55^{\mathrm{a}}$ \\
\hline & & $\mathrm{C}$ & $6.81 \pm 0.132$ & $10.9 \pm 1.03$ & $10.91 \pm 0.792$ & $110.57 \pm 1.46$ \\
\hline \multirow{3}{*}{ IV } & \multirow{3}{*}{ Curative } & A & $1.119 \pm 0.143$ & $1.35 \pm 0.132$ & $1.86 \pm 0.036$ & $79.27 \pm 1.78$ \\
\hline & & $\mathrm{B}$ & $4.89 \pm 0.112^{\mathrm{a}}$ & $4.91 \pm 0.023^{\mathrm{a}}$ & $9.90 \pm 0.632^{\mathrm{a}}$ & $132.16 \pm 0.98^{\mathrm{a}}$ \\
\hline & & $\mathrm{C}$ & $3.61 \pm 0.314^{\mathrm{c}}$ & $3.49 \pm 0.155^{c}$ & $3.88 \pm 0.181^{\mathrm{c}}$ & $95.12 \pm 1.66^{\mathrm{c}}$ \\
\hline
\end{tabular}

A = before implantation; B = after 30 days of Implantation; C = after treatment (distilled water / aqueous extract)

$P<0.001$ compared to (a) pre implantation values, (b) between II and I (after 30 days of implantation) and (c) between IV and III (after 60 days of implantation)

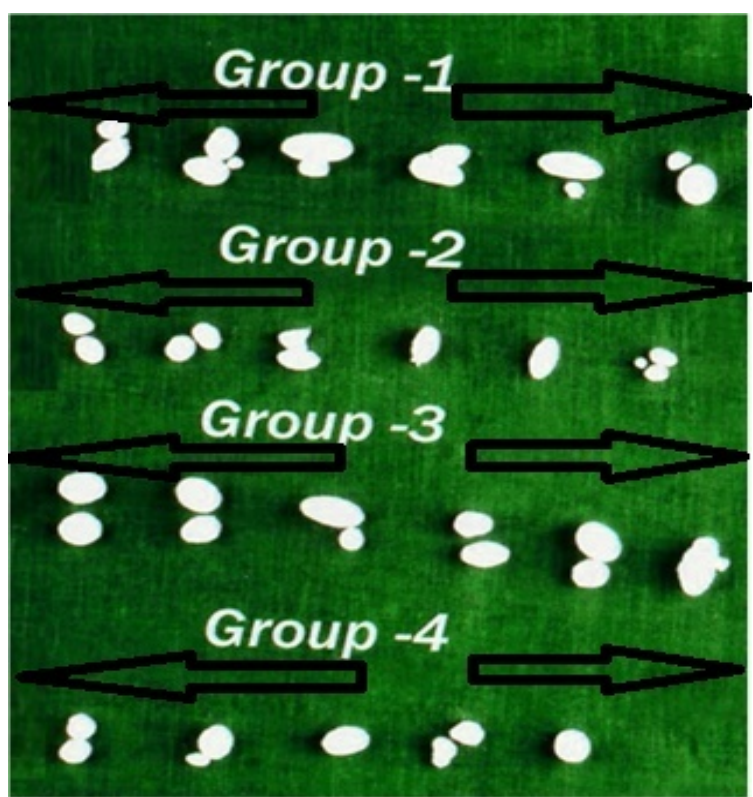

Figure 1. Comparison of stone material deposited on zinc discs in various groups

These results support the significant effect of aqueous extract of Melia azadirachta in preventing the formation and also in dissolving the pre-formed magnesium ammonium phosphate type of stones.

\section{Discussion}

It has been well documented that calculi disease affects $12 \%$ of the world population [27]. The disease frequency tends to increase in the Western countries. Many research laboratories are pursuing investigations in urolithiasis in preclinical and clinical areas. Urolithiasis is generally considered to be multifactorial problem and influenced by metabolism, lifestyle, occupation, nutrition, clinical status, medication etc.

Herbal drugs claim many promising remedies in urolithiasis [27]. Systematic, scientific evaluation has been done only on a few. In the present study an attempt was made to establish the scientific proof of the antiurolithiatic activity of Melia azadirachta aqueous extract using the zinc disc implantation model in male albino rats.

Male rats were selected to induce urolithiasis because the urinary system of male rats resembles that of humans [28] and also earlier studies have shown that the amount of stone deposited in female rats was significantly less [29].

Urinary stone formation takes place due to a change in urinary chemistry such as hypercalciuria and hyperoxaluria, leading to urinary supersaturation which later crystallizes, aggregates and ends up in stone formation [30]. 
Renal calculi in both humans and hyperoxaluria rats are located on renal papillary surfaces and consist of an organic matrix and crystals of various minerals. The matrix is intimately associated with the crystals and contains substances that can promote as well as inhibit. Osteopontin, Tamm-Horsfall protein, bikunin and prothrombin fragment-1 have been identified in matrices of both human and rat stones. Hyperoxaluria can provoke calcium oxalate urolithiasis in both humans and rats. Oxalate metabolism is considered to be almost identical between rats and human [31].

Although, there are different methods to induce calcium oxalate crystal deposition in the kidneys like administration of hyperoxaluric agents such as sodium oxalate, ethylene glycol, hydroxyl-proline [32] and pyridoxin depletion they suffer from their own limitations, like high incidence of nephrotoxicity, metabolic acidosis and occurrence of calculi in renal cortex that is situation opposite as found in humans urolithiasis.

The foreign body insertion technique was adopted for production of urolithiasis based on the earlier observation that a foreign body when present in the bladder acts as a nidus around which stone deposition takes place. Round zinc discs of $4 \mathrm{~mm}$ diameter were chosen as the foreign body implant [19]. The insertion was a simple procedure of slipping the disc into the urinary bladder through a small nick at the apex followed by closure with a single stitch. Bladder was selected the site of implantation, because it is technically much easier to place an implant there than in other locations such as kidneys. Though some subtle differences in stone formation definitely exist throughout the tract, the process of stone growth is believed to be fundamentally the same in the bladder as in all parts of the urinary tract.

In our antiurolithiatic study all the four groups showed a considerable amount of stone deposits on the zinc discs, proving the validity of foreign body implantation technique as an experimental model of urolithiasis. The stones formed were of magnesium ammonium phosphate type with traces of calcium and oxalate [17].

On administration of aqueous extract of Melia azadirachta the deposition of urinary calculi in both the preventive and curative groups was significantly reduced when compared to their respective control groups. The extract showed a preventive activity of $59 \%$ and a curative activity of $46 \%$ against magnesium ammonium phosphate type of stones. This indicates the antiurolithiatic activity of Melia azadirachta in preventing both the formation of stones and also in dissolving the preformed stones which are in conformity with previous studies of Shah et al. [33].

The type of stone formed in human subjects can be predicted from the $\mathrm{pH}$ of the fasting urine. Crystalluria is $\mathrm{pH}$ dependent. Dissolution of calculi can be achieved by alteration in urinary $\mathrm{pH}$. If the $\mathrm{pH}$ is acidic 5.0 or below, the stones likely to form are of uric acid type, if 5.0-6.5 calcium oxalate type and if alkaline (above 7) indicates crystals of magnesium ammonium phosphate [17].

The $\mathrm{pH}$ of the urine in the antiurolithic study was increased from initial $\mathrm{pH}$ 6.0-7.0 to 7.5-8.5 upon the formation of stones on the foreign body. This suggests that alkaline urine tends to precipitate magnesium, which may complex with ammonium and phosphate excreted in urine. Treatment with aqueous extract of Melia azadirachta reduced the $\mathrm{pH}$ values to 6.5-7.5 supporting the decrease in stone weight and urinary excretion of stone forming ions in antiurolithiatic study, indicating the influence of the extract in dissolving urinary calculi [17]. All this supports the effectiveness of the aqueous extract of Melia azadirachta against prevention of stone formation and its ability to dissolve preformed stones. Biochemical changes as reflected in the urine chemistry are very important to understand about the pathogenesis of stone formation, as well as design some treatment for dissolution or prevention of stones [33].

The present investigation showed an increase of urine output, which dilutes the concentration of urinary electrolytes resulting in lesser chances of precipitation of calcium and phosphorus. The excretion of oxalate and calcium were increased in curative group animals which is consistent with the previous reports [33,34]. Increased urinary calcium is a factor favouring the nucleation and precipitation of calcium oxalate or apatite (calcium phosphate) from urine and subsequent crystal growth [35]. However, the aqueous extract of Melia azadirachta lowered the levels of oxalate as well as calcium excretion, which is beneficial in preventing calculi formation.

An increase in urinary excretion of calcium and oxalate was observed along with the formation of calcium oxalate type of stones. In the formation of magnesium ammonium phosphate type of stones an increase in urinary excretion of magnesium and phosphate was observed [33].

A significant increase in urinary excretion of calcium, oxalate, magnesium and phosphate was observed four weeks after implantation of foreign body. The increase in urinary excretion of calcium, oxalate, magnesium and phosphate in the present study may be due to the formation of mixed type of stones, magnesium ammonium phosphate and traces of calcium and oxalate. The reason may be the elevated magnesium level has prevented the deposition of calcium oxalate where magnesium has formed a soluble complex with oxalate and has decreased the ability to form calcium oxalate which was in accordance with reports of Moor and Gowland [36].

Treatment with aqueous extract of Melia azadirachta caused a significant reduction in urinary excretion of calcium, oxalate, magnesium and phosphate in both the preventive and curative group animals, when compared to their respective controls. This explains the effect of the aqueous extract of Melia azadirachta in both preventing and also in dissolving the pre-formed magnesium ammonium phosphate type of stones.

The possible mechanisms could be due to the antiurolithiatic, antioxidant, diuretic, nephroprotective constituents present in Melia azadirachta. Further studies are required to explicate the possible chemical composition and the mechanism(s) that are responsible for antiurolithiatic activity.

From the present study it is concluded that the formed urinary stones could be dissolved with aqueous extract Melia azadirachta and without the aid of surgical intervention. While it may not be possible straightway to altogether dispense with surgical and other invasive procedures, the use of antiurolithiatic drugs is definitely going to revolutionize the treatment of urinary stones.

\section{Acknowledgement}


The authors sincerely acknowledge Priyadarshini Institute of Pharmaceutical Sciences and Hindu College of Pharmacy, Guntur, India for providing necessary facilities. We also thank Dr V. Jaya, Department of Botany, Hindu College, Guntur. Andhra Pradesh, India, for authentication of plant sample.

\section{References}

[1] Anderson, R.A, "A complementary approach to urolithiasis prevention,” World Journal of Urology, 20. 294-301. 2002.

[2] Trivedi, R.C., Reber, L., Berta, E. and Stong, L, "New enzymatic method for serum uric acid at $500 \mathrm{~nm}$,” Clinical Chemistry, 24 (11). 1908-1911. Dec. 1978.

[3] Tiselius, H.G., Vernhorst, E., Carlström, K., and Larsson, L, "Urinary oxalate excretion to during anti-androgenic therapy," Investigative Urology, 18 (2). 110-111. Sep. 1980.

[4] Anderson R.A, “A complementary approach to urolithiasis prevention,” World Journal of Urology, 20 (5). 294-301. Oct. 2002.

[5] Leusmann, D.B., Blaschke, R., and Schmandt, W, "Results of 5035 stone analyses: a contribution to epidemiology of urinary stone disease," Scandinavian Journal of Urology, 24 (3). 205-210. 1990.

[6] Lorentz, K, "Improved determination of serum calcium with ortho cresolphthalein complexone,” Clinica Chimica Acta, 126 (3). 327334. Dec. 1982.

[7] Gindi, S., Chandu, B.R., Dasari, V., and Bharga, B.R.G, "Exploitation of antiurolithiatic activity of Macrotyloma uniflorum on rats,” Pharmabuzz, 3. 12-14. Dec 2008.

[8] Gindi, S., Methra, T., Chandu, B.R., Boyina, R., and Dasari, V, "Antiurolithiatic and invitro anti-oxidant activity of leaves of Ageratum conyzoides in rat," World Journal of Pharmacy and Pharmaceutical Sciences, 2 (2). 636-649. Mar 2013.

[9] Kokate, C., Purohit, A.P., and Gokhale, S.B, Pharmacognosy, Nirali Prakashan, New Delhi, 2010, 10. 28-10. 29.

[10] Negi, P.S., Jayaprakasha, G.K., and Jena, B.S, "Distribution and introduction cultivation state of Azadirachta indica," Food Chemistry, 80. 293-297. Jan. 2002.

[11] Ali, A, Textbook of Pharmacognosy, Publication and Information Directorate, New Delhi, 1993, 381-384.

[12] Prieto, P., Pineda, M., and Aguilar, M, “Activity of a standardized neem (Azadirachta Indica) seed extract on the rodent malaria parasite plasmodium berghei," Analytical Biochemistry, 269. 337341. May. 1999.

[13] Britto, A.J., and Sheeba, D.H, “Azadiracta indica juss - a potential antimicrobial agent," International Journal of Applied Biological and Pharmaceutical Technology, 2 (3). 4550-4557. Jul. 2011.

[14] Eshrat, H., and Ali, M, "Using traditional Indian anti-diabetic plant Azadirachta Indica," Indian Journal of Clinical Biochemistry, 17. 115-123. Jul. 2002.

[15] Rabiu, H., and Subhasish, M, "Investigation of in-vitro anthelmintic ativity of Azadirachta indica leaves,” International Journal of Drug Development Research, 3 (4). 94-99. Oct. 2011.

[16] Vermulen, C.W, Cancer and Harmones, essays in experimental biology, Universities of Chicago Press, Chicago, 1968, 255.

[17] Barbasa, C., Garciaa, A., Saavedraa, L., and Muros, M, "Urinary analysis of nephrolithiasis markers,” Journal of Chromatography B, 781. 433-455. Dec. 2002.
[18] Bauer, J.D, Clinical laboratory methods, B1 Publications Ltd., New Delhi, 1990, 511-512.

[19] Singh, P.K., Patil, C.R., Harlalka, G.V., and Gaud, N.P, "Zinc disc implantation model of urinary bladder calculi and humane endpoints,” Laboratory Animals, 44 (3). 226-230. Jul. 2010.

[20] Ecobichon, D.J, The basis of toxicology testing, CRC Press, New York, 1997, 43-86.

[21] Vyas, N., and Argal, A, "Antiurolithiatic Activity of Extract and Oleanolic Acid Isolated from the Roots of Lantana camara on Zinc Disc Implantation Induced Urolithiasis,” ISRN Pharmacology, vol. 2013, Article ID 951795, 5 pages, 2013.

[22] Henry, J.R., Cannan, D.C., and Winkllman, J.W, Clinical chemistry principle and techniques, Harper and Row, NewYork, 1974, 723-727.

[23] Grove, W.J., Vermeulen, C.W., Goetz, R., and Ragins, H.D, "Experimental urolithiasis II. The influence of urine volume upon calculi experimentally produced upon foreign bodies," The Journal of Urology, 64 (4). 549-554. Oct. 1950.

[24] Prasad, K.V.S.R.G., Bharathi, K., and Srinivasan, K.K, "Evaluation of Rotula aquatica Lour for antilithiatic activity in albino rats," Indian Drugs, 30(8). 398-404. Aug. 1993.

[25] Souccar, C., Viel, T.A., Domingos, C.D., Monteiro, A.P.S., LimaLandman, M.T.R., Lapa, A.J, "Evaluation of the antiurolithiatic activity of the extract of Costus spiralis Roscoe in rats," Journal of Ethnopharmacology, 66. 193-198. Aug. 1999.

[26] Vermeulen, C.W., Grove, W.J., Goetz, R., Ragins, H.D., and Correl, N.O, "Experimental urolithiasis. I. Development of calculi upon foreign bodies surgically introduced into bladders of rats," Journal of Urology, 64 (4). 541-548. Oct. 1950.

[27] Prasad, K., Sujatha, D., and Bharathi, K, "Herbal drugs in urolithiasis-a review,” Pharmacognosy Research, 1. 175-179. May. 2007.

[28] Khan, Z.A., Assiri, A.M., Al-Afghani H.M., and Maghrbi, T.M, "Inhibition of oxalate nephrolithiasis with Ammivisnaga (Alkhillah),” International Urology and Nephrology, 33 (4). 605-608. 2001.

[29] Khan, S.R, “Crystal induced inflammation of the kidneys results from human studies, animal models and tissue culture studies. Clinical and Experimental Nephrology, 8 (2). 75-88. Jun. 2004.

[30] Michell, A.R, "Urolithiasis-historical, comparative and pathophysiological aspects: a review," Journal of the Royal Society of Medicine, 82. 669. Nov. 1989.

[31] Khan. S.R., and Hackett, R.L, "Calcium oxalate urolithiasis in the rats: Is it a model for human stone disease? A review of recent literature,” Scanning Electron Microscopy, Pt 2. 759-774. 1985.

[32] Khan, S.R., and Glenton, P.A, "Experimental induction of calcium oxalate nephrolithiasis in mice," Journal of Urology, 184 (3). 1189-1196. Sep. 2010.

[33] Shah, J.G., Patel, B.G., Patel, S.B., and Patel, R.K, "Antiurolithiatic and antioxidant activity of Hordeum vulgare seeds on ethylene glycol-induced urolithiasis in rats," Indian Journal of Pharmacology, 44 (6). 672-677. 2012.

[34] Divakar, K., Pawar, A.T., Chandrasekhar, S.B., Dighe, S.B., and Divakar, G, "Protective effect of the hydro-alcoholic extract of Rubia cordifolia roots against ethylene glycol induced urolithiasis in rats," Food Chemistry and Toxicology, 48 (4). 1013-1018. Apr. 2010.

[35] Roger, K., Low, M.D., and Stoller, M.L, "Uric acid nephrolithiasis,” Urology Clinical of North America, 24. 135-148. Feb. 1997.

[36] Moore, S., and Gowland, G, “The immunological integrity of matrix substance A and its possible detection and quantification in urine,” Brazilian Journal of Urology, 47. 489-494. Oct. 1975. 